\title{
Development and Characterization of Thermal Insulation Geopolymer Foams Based on Fly Ash
}

\author{
Michał Łach ${ }^{1, *}$, Janusz Mikuła $^{1}$, Wei-Ting Lin $^{2}$, Patrycja Bazan $^{1}$, Beata Figiela ${ }^{1}$, Kinga Korniejenko ${ }^{1}$ \\ ${ }^{1}$ Institute of Materials Engineering, Faculty of Materials Engineering and Physics, \\ Cracow University of Technology, Cracow, Poland \\ ${ }^{2}$ Department of Civil Engineering, National Ilan University, Yilan, Taiwan \\ Received 18 February 2020; received in revised form 30 April 2020; accepted 04 June 2020
}

DOI: https://doi.org/10.46604/peti.2020.5291

\begin{abstract}
The main purpose of the article is to present the differences in the parameters of geopolymer foams obtained in the same way, which is associated with difficulties in controlling the foaming process. Difficulties in controlling the foaming process of geopolymers are the direct reason for the lack of implementation of such materials nowadays. The article shows the results for experimental research, especially research into insulation, physical, and mechanical properties for the designated foamed materials. Microspheres (75\%), sand (5\%) and fly ash (20\%) were used to produce foamed geopolymers. Hydrogen peroxide was the foaming agent. Heat conduction coefficients of 0.08-0.07 $\mathrm{W} / \mathrm{mK}$ were obtained. The material density was obtained at the level of $363-375\left[\mathrm{~kg} / \mathrm{m}^{3}\right]$ and the compressive strength was 520-683 [kPa]. The results showed that geopolymers can be a good alternative to conventional insulation materials, but the foaming technology should be developed so that it is stable and allows for reproducible material parameters.
\end{abstract}

Keywords: geopolymer, thermal insulation, mechanical properties, inorganic foams

\section{Introduction}

For many years, scientists have been developing insulation materials that have the best durability, non-flammability, and a relatively low price. One of such materials is foamed geopolymer. However, in order to make a foamed geopolymer be a real alternative to replace the currently used insulation materials, it must be met the relevant strength standards and passed the non-flammability test. Different values of thermal conductivity and strength of foamed geopolymers are given in scientific paper. Nevertheless, they usually differ from the thermal conductivity of popular materials such as polystyrene [1-2]. The best values in terms of thermal conductivity that scientific studies have shown so far are those in studies by Liefke [3]. This is a material called TROLIT, which has a thermal conductivity of $0.037 \mathrm{~W} / \mathrm{mK}$. The selected parameters of this material are presented in Table 1. Nonetheless, since the material was first described [3-4], such a good parameter for geopolymer foams has not been noted again. Scientists have tested a lot of compositions by using different materials and are trying to create the optimal material.

A good quality of geopolymer insulating material which has density of $313 \mathrm{~kg} / \mathrm{m}^{3}$, a compressive strength of $0.63 \mathrm{MPa}$, and a thermal conductivity $0.07 \mathrm{~W} / \mathrm{mK}$ was obtained, for example, from a mixture of metakaolin and biomass ashes [5]. Usually various types of additives are introduced such as diatomite [6]. The replacement of the diatomite in the formulation affects the morphological structure of the foams and then influences their mechanical properties due to a different type of

* Corresponding author. E-mail address: michal.lach@pk.edu.pl 
chemical bond between sodium silicate and the solid phase. In particular, the mechanism of consolidation of hybrid foams based on the diatomite has changed from geopolymerisation to silicate polycondensation. Therefore, the strength parameters improved with the increase of diatomite content [6]. Metakaolin-based geopolymers foamed with $\mathrm{H}_{2} \mathrm{O}_{2}$, which the amounts from 0.25 wt. $\%$ up to 1.25 wt. $\%$, were characterised by a compressive strength from $6 \mathrm{MPa}$ (for $0.25 \% \mathrm{H}_{2} \mathrm{O}_{2}$ ) to $0.36 \mathrm{MPa}$ (for $1.25 \% \mathrm{H}_{2} \mathrm{O}_{2}$ ). Thermal conductivity was from $0.298 \mathrm{~W} / \mathrm{mK}$ (for $0.25 \mathrm{wt} \% \% \mathrm{H}_{2} \mathrm{O}_{2}$ ) up to $0.172 \mathrm{~W} / \mathrm{mK}$ (for $1.25 \mathrm{wt} . \% \mathrm{H}_{2} \mathrm{O}_{2}$ ) [7]. To obtain the optimal parameters of the geopolymer foams, the metakaolin and fly ash are often used together. Samson and Cyr [8] proved that the most optimal composition for their type of raw materials was $62.5 \%$ metakaolin with $12.5 \%$ fly ash and $25 \%$ activator. The composition was expanded using $\mathrm{H}_{2} \mathrm{O}_{2}$ in amounts of 1, 1.5, and 2 wt.\% and densities from 225 to 506 $\mathrm{kg} / \mathrm{m}^{3}$ and thermal conductivities from 0.07 to $0.12 \mathrm{~W} / \mathrm{mK}$ were obtained. These studies have also shown that the use of surfactants has a huge impact on the porous structure [8]. It is also possible to use rice husks as a foaming agent [9]. Additives to geopolymers are also very often introduced to improve strength properties. For instance, strength parameters of geopolymers can be improved by adding the lime and the gypsum [10]. Fly ash and metakaolin beyond their use for not only use in the production of geopolymers, but also used in other technologies, for example, they can be used as a filling material in mineral composites [11].

Table 1 Physical characteristics of TROLIT ${ }^{\mathrm{TM}}$ foams $[1,2]$

\begin{tabular}{|c|c|}
\hline Bulk density $\left[\mathrm{kg} / \mathrm{m}^{3}\right]$ & $200-800$ \\
\hline Max. temperature of application $\left[{ }^{\circ} \mathrm{C}\right]$ & 1000 \\
\hline Max. thermostability $\left[{ }^{\circ} \mathrm{C}\right]$ & 1200 \\
\hline Thermal conductivity [W/mK] & $\geq 0.037$ (depending on density) \\
\hline Pore parameter [mm] & $0.5-3.0$ \\
\hline Fire protection [DIN 4102] & Inflammable, classification A1 \\
\hline Compressive strength $\left[\mathrm{N} / \mathrm{mm}^{2}\right]$ & $0.5-2.0$ \\
\hline Tensile strength $\left[\mathrm{N} / \mathrm{mm}^{2}\right]$ & $\approx 250$ \\
\hline
\end{tabular}

This study presents the results obtained from foamed geopolymer materials based on fly ash. The results of compressive and bending strength tests depending on the density of the obtained materials are to be presented. In this study, the authors want to draw the problems when foaming geopolymers occur and show the fact that despite of attempting to control foaming conditions, the process will be different each time. The material described in this research differs significantly from that described in the literature because it contains up to $75 \%$ of microspheres. Only $20 \%$ by the weight of fly ash was subjected to the foaming process. This material which is the combination of the open porosity obtained from foaming geopolymer and closed porosity obtained by microspheres is produced.

\section{Materials and Methods}

Fly ash from the Skawina CHP production plant was used as a precursor. The oxide composition of the precursor, determined by the XRF (X-Ray Fluorescence), is shown in Table 2.

Table 2 Oxide content of the fly ash from the Skawina CHP plant

\begin{tabular}{|c|c|c|c|c|c|c|c|c|c|c|c|}
\hline Oxide & $\mathrm{SiO}_{2}$ & $\mathrm{Al}_{2} \mathrm{O}_{3}$ & $\mathrm{Fe}_{2} \mathrm{O}_{3}$ & $\mathrm{CaO}$ & $\mathrm{MgO}$ & $\mathrm{Na}_{2} \mathrm{O}$ & $\mathrm{K}_{2} \mathrm{O}$ & $\mathrm{SO}_{3}$ & $\mathrm{TiO}_{2}$ & $\mathrm{P}_{2} \mathrm{O}_{5}$ & $\mathrm{BaO}$ \\
\hline Content [\%] & 55.89 & 23.49 & 5.92 & 2.72 & 2.61 & 0.59 & 3.55 & 0.16 & 1.09 & 0.82 & 0.20 \\
\hline
\end{tabular}

The geopolymers were produced by using technical sodium hydroxide flakes and an aqueous sodium silicate solution of R-145 module 2.5 , with a molar density of about $1.45 \mathrm{~g} / \mathrm{cm}^{3}$. The mixture did not use distilled water. The alkaline solution was prepared, for instance, the solid sodium hydroxide was poured over an aqueous solution of sodium silicate and water. The solution was thoroughly mixed and allowed to equilibrate until a constant concentration and temperature were achieved.

The geopolymer foams were prepared in such a way that solid constituents, such as fly ash, microspheres, and sand were mixed until reaching a homogeneous state, and afterwards an alkaline solution -10M sodium hydroxide solution with the addition of sodium silicate in the ratio 1:2.5 was introduced. The material was mixed for 10 minutes. An appropriate amount of 
hydrogen peroxide was then introduced and continuously mixed for approx. 1 minute. After the mixing process was complete, the material was poured into a mould and exposed at a temperature of $75^{\circ} \mathrm{C}$ for a period of 24 hours. Subsequently, it was the heating process; the element was dismantled and stored under laboratory conditions for a period of 28 days in order to obtain full strength. Examples of the foamed geopolymer materials are presented in Figs. 1 and 2.

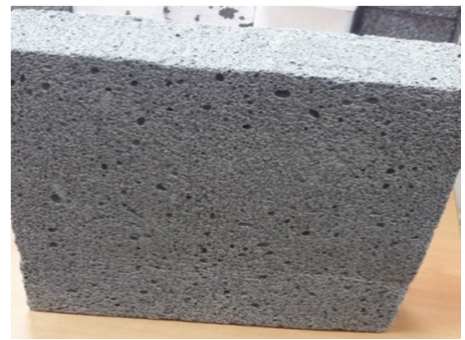

Fig. 1 An example of foamed geopolymer panels

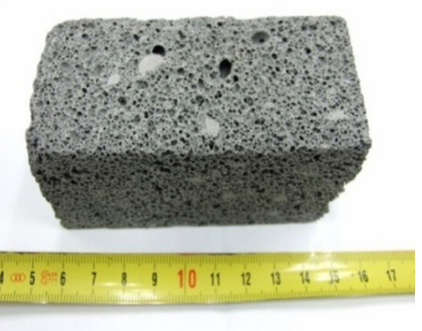

Fig. 2 An example of foamed geopolymer panels

The thermal conductivity coefficient was calculated in accordance with PN-EN 12667:2002. The measurements were carried out under the steady-state conditions of heat transfer at an average sample temperature amounting to $10^{\circ} \mathrm{C}$, for the samples which dimensions were $300 \times 300 \times 100 \mathrm{~mm}$. The applied temperature difference was $20^{\circ} \mathrm{C}$ for the thickness of the sample $\left(\mathrm{T} 1=0^{\circ} \mathrm{C}, \mathrm{T} 2=20^{\circ} \mathrm{C}\right.$, Tmean $\left.=10^{\circ} \mathrm{C}\right)$. The tests were conducted in a closed test chamber (having thermally-insulated walls) with the one-sample plate apparatus HFM 436/3/0, NETZSCH, provided with a heat-flow density sensor. The results were compared with the certified reference values IRMM-440 no 30. The bulk density of the product was calculated as a mass ratio per unit volume of the sample, without reference to the certified specimen.

The flexural strength test was conducted in accordance with EN 12089 on samples of dimensions $300 \times 50 \times 150 \mathrm{~mm}$. Compressive strength tests were carried out according to EN 826 on samples of dimensions $50 \times 50 \times 50 \mathrm{~mm}$.

\section{Results}

The tests were implemented for one and the same composition, whose composition and heat transfer coefficients are given in Table 3. However, three different variants of geopolymer panels were obtained due to the different courses of the foaming process. Five different samples and measurements were made for each variant. For the obtained results, the standard deviation was calculated and the values of which were quite huge and exceeded several percent because of the heterogeneous porosity of the material. Macroscopic and visual observations showed that the distribution of pores in the samples is uneven. The authors of the study often face the problem of uneven distribution of pores and their different sizes. The process of foaming geopolymers is difficult to control and attention. Moreover, it should be paid to stabilise the produced foams. These problems cause a large dispersion in the obtained test results, despite the same process and composition, different results are obtained.

Table 3 Composition of foamed geopolymers

\begin{tabular}{|c|c|c|c|}
\hline & Composition & Amount $\mathrm{H}_{2} \mathrm{O}_{2}$ & Thermal conductivity [W/mk] \\
\hline GeoFoam1 & $75 \%$ microspheres $+5 \%$ sand $+20 \%$ flyash & $3 \% \mathrm{wt}$. & 0.08094 \\
\hline GeoFoam 2 & $75 \%$ microspheres $+5 \%$ sand $+20 \%$ flyash & $3 \% \mathrm{wt}$. & 0.07430 \\
\hline GeoFoam3 & $75 \%$ microspheres $+5 \%$ sand $+20 \%$ flyash & $3 \% \mathrm{wt}$. & 0.07492 \\
\hline
\end{tabular}

Table 4 Test results of mechanical properties of obtained geopolymer foams

\begin{tabular}{|l|c|c|c|}
\hline & Density $\left[\mathrm{kg} / \mathrm{m}^{3}\right]$ & Flexural strength $[\mathrm{kPa}]$ & Compressive strength $[\mathrm{kPa}]$ \\
\hline GeoFoam1 & $375.8 \pm 5.9$ & $447.61 \pm 85.6$ & $683.3 \pm 28.87$ \\
\hline GeoFoam2 & $363.8 \pm 7.3$ & $362.91 \pm 72.2$ & $520.0 \pm 34.64$ \\
\hline GeoFoam3 & $364.0 \pm 18.0$ & $369.38 \pm 74.8$ & $526.7 \pm 80.8$ \\
\hline
\end{tabular}

Table 4 and Fig. 3 show the results of testing the strength properties of the foamed geopolymer panels. The consequences of tests on the flexural strength and compressive strength are presented, depending on the density of the geopolymer material. The highest value of flexural strength is $447 \mathrm{kPa}$ and the compressive strength is $683 \mathrm{kPa}$. 


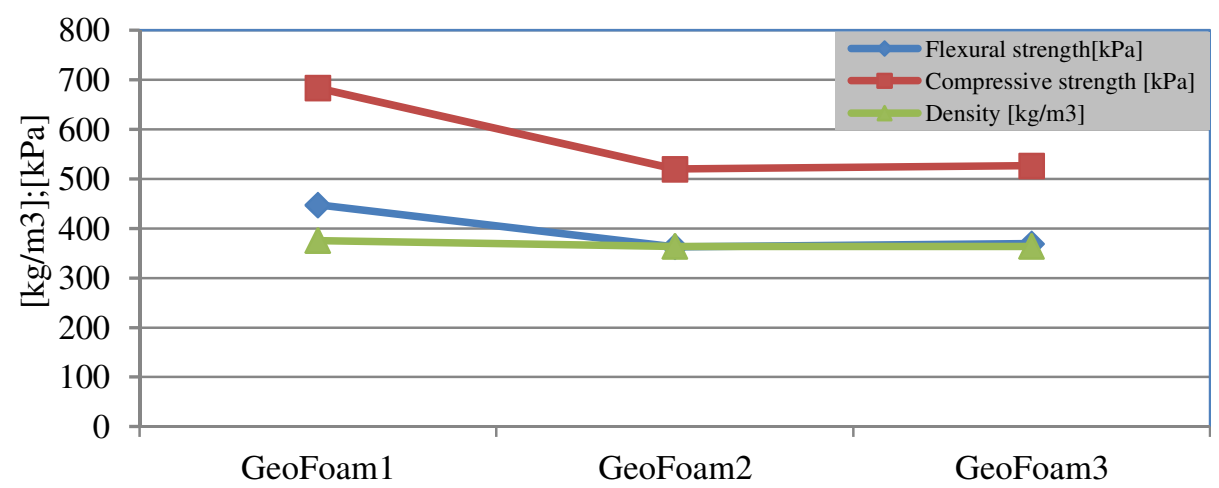

Fig. 3 Graphical representation of the density and strength of the materials

It is the results of the SEM / EDS scanning microscope below showing the morphology for one of the samples to illustrate the heterogeneity of the material (Figs. 4 and 5). Point chemical composition analyses and visual observations show that not all the fly ash particles have been expanded. Their composition indicates a smaller amount of $\mathrm{Na}$ and an increased amount of Ca (point 4). The observed structure is heterogeneous.

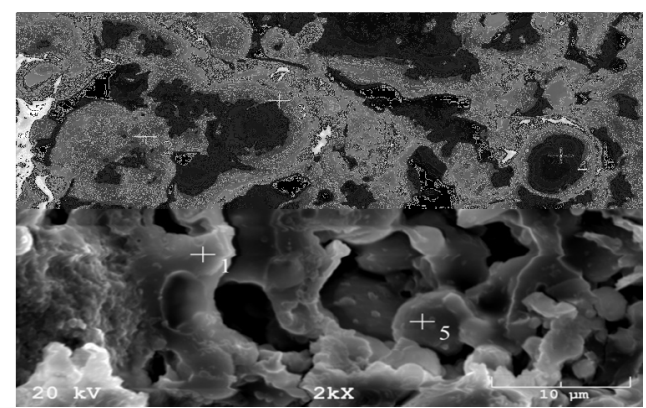

Fig. 4 Microstructure of foamed geopolymer

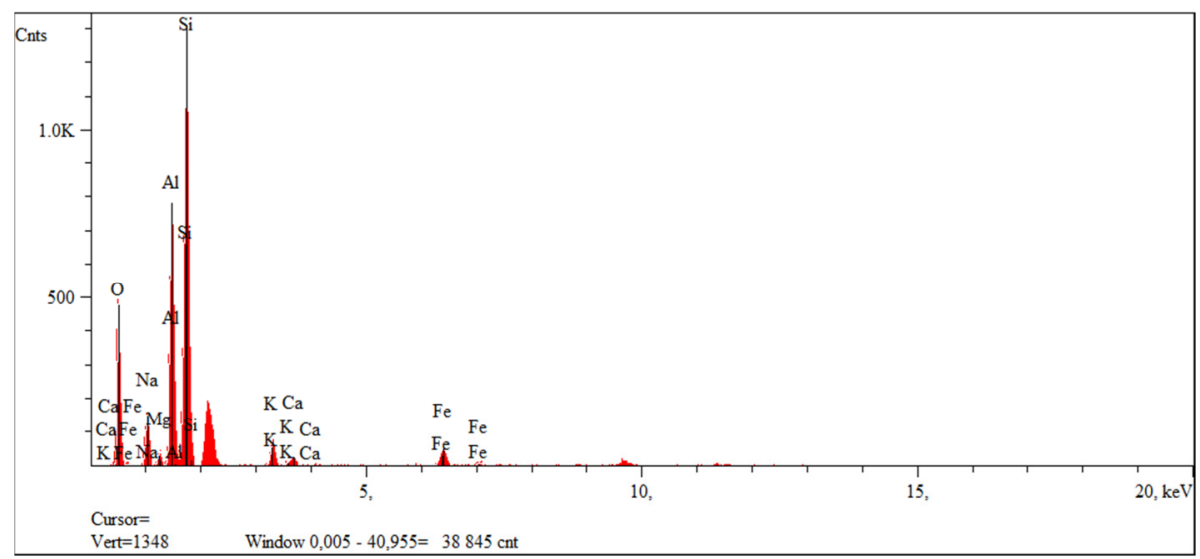

(a) Point 1

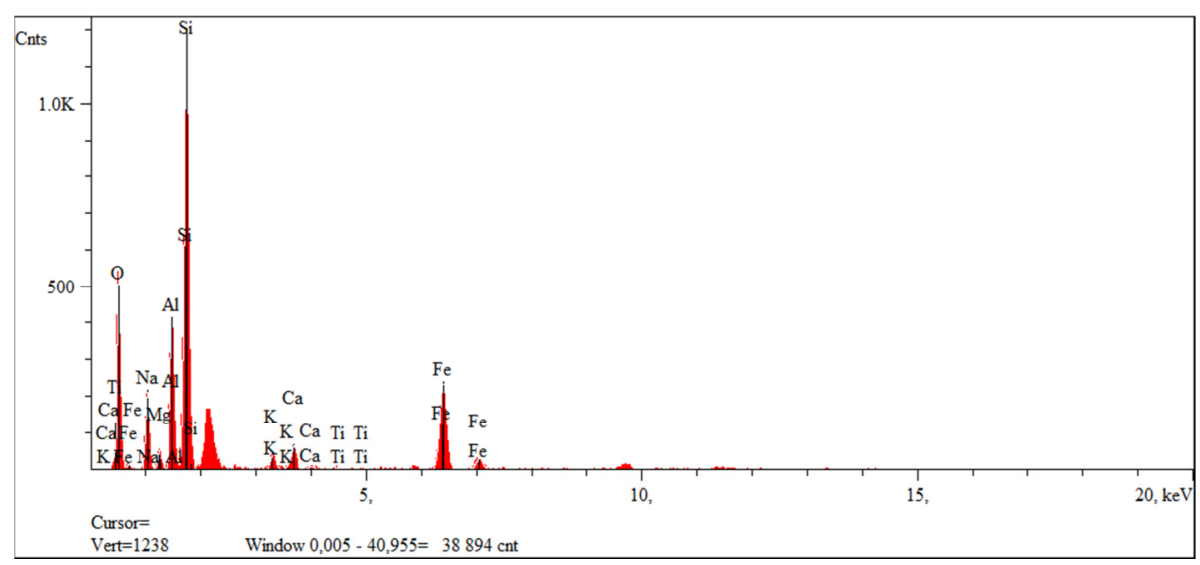

(b) Point 2

Fig. 5 Chemical point analysis 


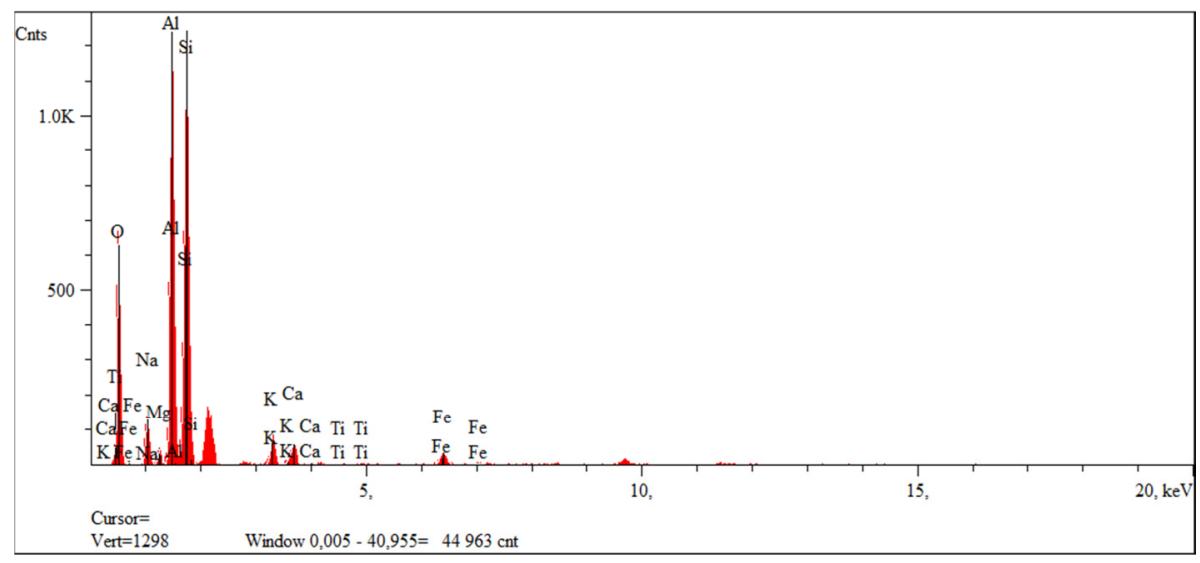

(c) Point 3

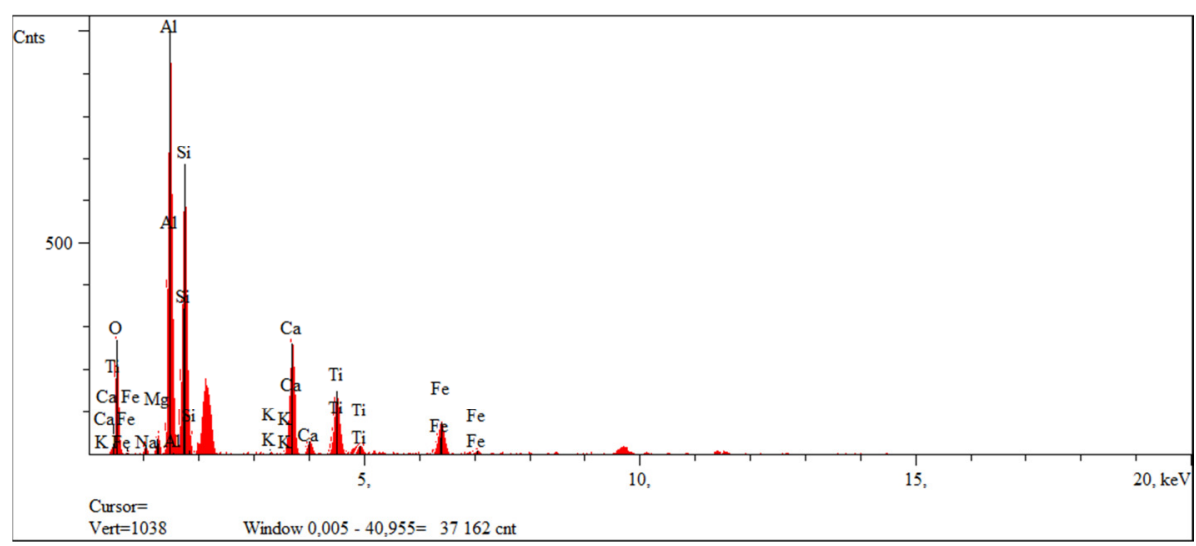

(d) Point 4

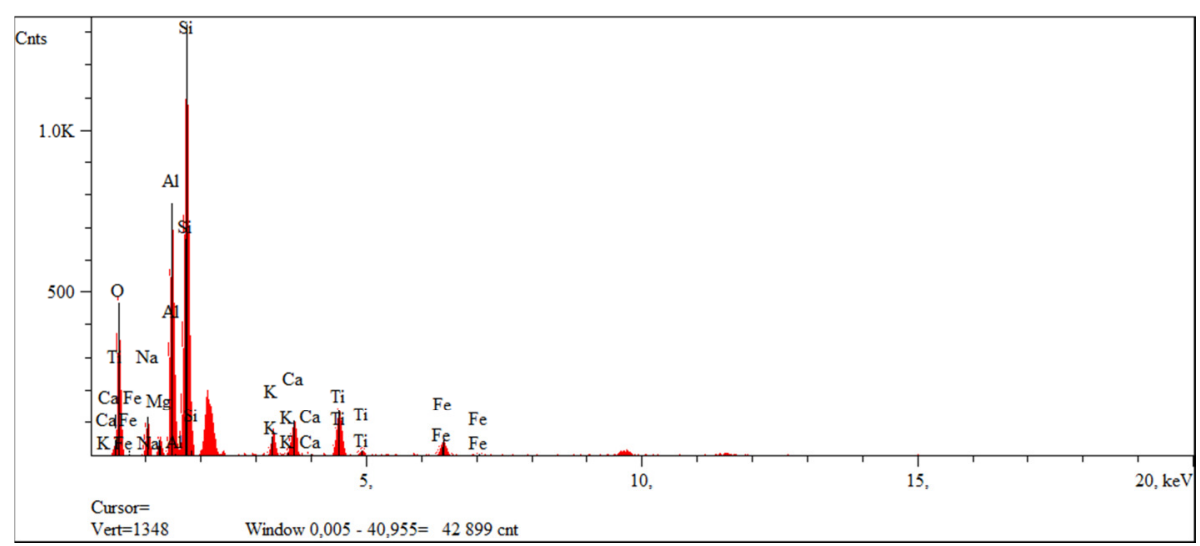

(e) Point 5

Fig. 5 Chemical point analysis (continued)

There are also variables at content points; for example, the $\mathrm{Fe}$ and $\mathrm{Si} / \mathrm{Al}$ ratios are variable. Obviously, all these parameters affect the quality of the geopolymer foams obtained. In the drawing, points 3-5 show spherical particles, probably microspheres used to make geopolymers. They are characterized by a much higher content of Al than the foamed structure revealed in points 1 and 2. Thanks to the introduction of hollow spherical particles in the form of microspheres, it was possible to achieve both open and closed pore structure.

The researchers would like to pay special attention to the heterogeneity of the obtained materials. The heterogeneity comes from the difficulties in controlling the foaming process and problems with the stabilization of the produced foams.

\section{Summary}

Figs. 1 and 2 show the geopolymer materials characterized by uneven pore size distribution. It's more distinctly visible in Fig. 2 due to the low stability of the pores produced and their tendency to join. Foamed structures disintegrate very quickly and 
create larger pores coming to the surface. This is one of the reasons for the great difficulty in foaming geopolymer materials. Scientists are attempting to incorporate various types of stabilizers into geopolymer foams. The uneven distribution of pores is also found in the photos from the scanning electron microscope in Fig. 4.

The geopolymer foams have similar density values in the range of $363-375 \mathrm{~kg} / \mathrm{m}^{3}$. Compressive and bending strengths vary for individual samples but to a small extent. Similarly, the thermal conductivity coefficient differs for individual tests. Despite the fact that the materials were made in the same way and their composition is identical, different parameters of the finished products were obtained. It is proved that the process of foaming geopolymers is very difficult to control. The lack of the stability of the obtained foams can lead to different parameters such as the heat transfer coefficient. Even small differences may have higher thermal conductivity coefficients in this case.

It should also be emphasized that in the presented research only $20 \%$ of fly ash was used to compose the geopolymer mixture and only these $20 \%$ of the components were subjected to the foaming process. If more fly ash and fewer microspheres were used, which additionally stabilize the produced foams, the differences in the results obtained would be greater. Difficulties in controlling the foaming process, foam stability, and uneven pore size distribution are one of the main reasons for the lack of commercial implementations of this type of material. All research achievements in this area, new experiences are the most beneficial and one should strive to overcome these problems.

The parameters of currently obtained foamed geopolymers are different, unfortunately, from the developed materials based on resins such as IRMM-440. These materials are characterized by a very low density of $66-74 \mathrm{~kg} / \mathrm{m}^{3}$ and a heat transfer coefficient of $0.029 \mathrm{~W} / \mathrm{mK}$. When designing the geopolymers, the researchers should seek to obtain such the attractive parameters.

The obtained thermal conductivity values of foamed geopolymers are better than when using the microwave method of foam production. When using microwaves to produce foamed geopolymers, it was possible to obtain a minimum thermal conductivity $0.2387 \mathrm{~W} \cdot \mathrm{m}-1 \cdot \mathrm{K}-1$ and higher density values [12].

\section{Conclusions}

Foam geopolymer materials based on fly ash are interesting alternatives to currently popular materials such as polystyrene, mineral wool, and glass. They are a non-flammable material characterized by relatively good insulation parameters. The tests showed that the geopolymer foams, at a density of $375 \mathrm{~kg} / \mathrm{m} 3$, have a compressive strength of about $0.68 \mathrm{MPa}$ and the bending strength of 0.45 MPa. As the density decreases, the strength properties decrease. It is expected that this material will soon be implemented on an industrial scale as an alternative for the currently used insulation materials in construction. Preparation for implementation, however, requires further research related to the stability and repeatability of the obtained geopolymer foams. It should also be striven to make it possible to use various waste materials for the production of foamed inorganic polymers.

\section{Acknowledgements}

This work was supported by the Polish National Centre for Research and Development under the LIDER Grant no: LIDER/31/0168/L-10/18/NCBR/2019.

\section{Conflicts of Interest}

The authors declare no conflict of interest. 


\section{References}

[1] M. Łach, K. Korniejenko, and J. Mikuła, "Thermal insulation and thermally resistant materials made of geopolymer foams," Procedia Engineering, vol. 151, pp. 410-416, December 2016.

[2] M. Łach, D. Mierzwiński, K. Korniejenko, and J. Mikuła, “Geopolymer foam as a passive fire protection,” MATEC Web of Conferences, vol. 247, pp. 1-6, December 2018.

[3] E. Liefke, "Industrial applications of foamed inorganic polymers," Geopolymere'99 Proceedings, : Institut Géopolymère, December 1999, pp. 189-200.

[4] J. Davidovits, Geopolymer chemistry and application, 4th ed. Saint-Quentin: Institut Géopolymère, 2015.

[5] A. N. Murri, V. Medri, E. Papa, L. Laghi, C. Mingazzini, and E. Landi, "Porous geopolymer insulating core from a metakaolin/biomass ash composite,” Environments, vol. 4, no. 4, pp. 1-13, December 2017.

[6] B. Liguori, I. Capasso, V. Romeo, M. D Auria, M. Lavorgna, D. Caputo, S. Iannace, et al., "Hybrid geopolymeric foams with diatomite addition: effect on chemico-physical properties," Journal of Cellular Plastics, vol. 53, no. 5, pp. 525-536, February 2017.

[7] N. A. Jaya, Y. M. Liew, M. M. A. B. Abdullah, and C. Y. Heah, "Porous metakaolin geopolymers with tailored thermal conductivity,” IOP Conference Series: Materials Science and Engineering, vol. 551, no.1, pp. 1-5, August 2019.

[8] G. Samson and M. Cyr, "Porous structure optimisation of flash-calcined metakaolin/fly ash geopolymer foam concrete," European Journal of Environmental and Civil Engineering, vol. 22, no. 12, pp. 1482-1498, April 2017.

[9] H. I. Riyap, C. N. Bewa, C. Banenzoué, H. K. Tchakouté, C. H. Rüscher, E. Kamseu, et al., "Microstructure and mechanical, physical and structural properties of sustainable lightweight metakaolin-based geopolymer cements and mortars employing rice husk," Journal of Asian Ceramic Societies, vol. 7, no. 2, pp. 199-212, April 2019.

[10] V. Sahu, A. Srivastava, and V. Gayathri, "Effect of lime and gypsum on engineering properties of badarpur fly ash," International Journal of Engineering and Technology Innovation, vol. 6, no 4, pp. 294-304, September 2016.

[11] R. V. Upadhyaya and T. G. Suntharavadivel, "Optimization of fly ash and metakaolin content in mineral based CFRP retrofit for improved sustainability,” International Journal of Engineering and Technology Innovation, vol. 9, no. 3, pp. 171-181, May 2019.

[12] M. Nadeem, E. Ulhaq, F. Ahmed, M. Asif Rafiq, G. Hameed Awan, and M. Zain-ul-Abdein, "Effect of microwave curing on the construction properties of natural soil based geopolymer foam," Construction and Building Materials, vol. 230, pp. 117074, January 2020.

Copyright $(\subset$ by the authors. Licensee TAETI, Taiwan. This article is an open access article distributed under the terms and conditions of the Creative Commons Attribution (CC BY-NC) license (https://creativecommons.org/licenses/by-nc/4.0/). 